\title{
Creativity: The Show Must Go On
}

\section{Maciej Karwowski}

Academy of Special Education, Poland

E-mail address: maciek.karwowski@gmail.com

\author{
Janina Uszyńska-Jarmoc \\ University of Bialystok, Poland \\ E-mail address: j.uszynska@uwb.edu.pl
}

ARTICLE INFO

\section{Keywords:}

Creativity literature

Paradigms in creativity research

Education for creativity

ISSN:

DOI: 10.15290/ctra.2014.01.01.01

\section{A B S T R A C T}

\begin{abstract}
In this opening editorial to the new peer-reviewed journal entitled "Creativity: Theories - Research - Applications," we present our vision, mission and the philosophy of this new journal in the field of creativity studies. As creativity researchers and editors, we start by identifying several gaps in the existing creativity literature and propose how a new journal could fill them. We conclude with an invitation to scholars worldwide to participate in the creation of this new, fascinating project.
\end{abstract}

\section{INTRODUCTION}

The great majority of all works devoted to creativity - including articles published in this first issue of the very first volume of Creativity: Theories - Research - Applications (CTRA) - start with a kind of invocation, calling creativity the fuel of economic and cultural growth, the source of flow and well-being, and the goal of functioning for parents, teachers, managers, politicians, and indeed everyone else. Even if such claims are heavily ideological, they do reflect a very special and specific attitude creativity researchers share in common - fascination or even love of their research topic. As creativity researchers are deeply engaged in, and strongly motivated to study the complex phenomena of creativity, they also need much more space than before to share their ideas, theories, research findings or even speculations. By creating this journal we aim at widening the number of possible outputs for creativity researchers and scholars interested in related phenomena. In this inaugural editorial we sketch our goals and plans, and invite potential contributors to consider publishing with us.

\section{Why a new journal? Five building blocks}

In the last few decades, the field of creativity studies has been growing rapidly. Decades ago scholars involved in exploring the antecedents, correlates, conditions and consequences of creative thinking and functioning published their works in two - now classic journals: the Journal of Creative Behavior and the Creativity Research Journal. In recent years at least five new, dedicated journals have appeared: starting with the APA Division 
10's Psychology of Aesthetics, Creativity, and the Arts, and including Thinking Skills and Creativity, Creativity and the Innovation Management, International Journal of Creativity and Problem Solving, Creativity and Human Development, as well as Creativity and Leisure: An Interdisciplinary and Cross-Cultural Journal. If we add to these titles several creativity-related journals open to creativity research, but focused for instance, on art or giftedness (Gifted Child Quarterly, High Ability Studies, Empirical Studies in the Arts, Imagination, Cognition and Personality, among others), the number becomes hard to ignore. Thus, readers may reasonably doubt and ask whether another journal is needed at all. Our role is not to convince the unconvinced, but here we would like to clarify and present our beliefs and arguments that guide the creation of this journal. We see at least five different building-blocks for this journal.

First, the great majority of all works published in creativity journals are quantitative in nature. The research is usually correlational or experimental, less often meta-analytical or historiometrical, but very rarely based on qualitative methods. We feel that space for creativity researchers who use qualitative methods is especially needed and we do hope that CTRA will provide such space.

Second, the main creativity periodicals rarely include theoretical articles. We see this as a serious obstacle and believe that CTRA may provide space for advanced, even controversial theoretical discussions about the main aspects of creativity theories, and generate constructive dialogue even about more speculative ideas.

Third, although creativity as a human activity and creativity research in general have no boundaries, in fact there is wide differentiation of creativity studies across the world. These different perceptions and paradigms in studying creativity have relatively rarely been taken into consideration (see Kaufman \& Sternberg, 2006). Some time ago, while editing a special issue of the International Journal of Creativity and Problem Solving (see Karwowski \& Glăveanu, 2013; Glăveanu \& Karwowski, 2013) we realized how many interesting studies on creativity are conducted in different parts of the world, and how rarely these studies are published in mainstream creativity journals. Thus, we do believe that CTRA will form a platform for sharing theoretical ideas, research results, and good practices of scholars from different parts of the world, not necessarily from just Western Europe and North America.

Fourth, creativity journals devote the majority of their space to presenting research papers. Theoretical papers are in the great minority, while there are almost no articles that deal with the practical applications of creative thinking in art, school or family. We hope that CTRA will provide a forum for researchers, and practitioners to share their ideas 
about the applications of creativity, as well as their own creative products.

Fifth, all creativity journals available on the market are in fact written from the perspective of one (rarely two) scholarly discipline - mainly psychology. Creativity, however, is not only a psychological phenomenon. Hence, we will devote our time and energy to encourage scholars from other fields, such as sociology, education, art, anthropology, or linguistics to share their ideas and present them in our pages. We are aware of the dangers of eclecticism, but we also believe that only a real dialogue between scholars from different fields and specializations can push the science of creativity further.

\section{What are we looking for?}

Every editor dreams about high-quality, top-tier papers. So do we. But we are also realistic, and fully aware that expecting that a new journal will receive a number of revolutionary submissions is naive. We do believe and hope that in the near future leading creativity scholars will consider CTRA as an output for their best work. Although we invite all scholars to share their research and theoretical ideas with us, at this point we should highlight three important matters: openness to the new generation of researchers, no harm in presenting null findings, and encouragement of replications.

Openness to the new generation. First and foremost, we would like to explicitly state that we especially warmly invite young scholars and graduate students to share their ideas with an international audience. We all know how competitive the contemporary world of science is and how difficult it is to publish a paper in a peer-reviewed journal. We offer fast turn-around and extremely competent referees-just take a look at our Editorial Board.

No harm in null findings. Our drawers are full of non-significant results without any real chance of getting to get published. Although null findings are always problematic, we are open to publishing highly-powered and well-developed studies, even when the result is inconsistent with the expectations, and not significant. We will encourage our reviewers to focus on the quality of the study itself, not the $p$ value. We do believe that literature brings overestimated effect sizes due to the file drawer problem, and we think it is worth publishing well-designed studies irrespective of the result.

Encouragement of replications. The recent movement toward replications in psychology and the more general discussion about the quality of research in the field of psychology of creativity (Makel, 2014) deals with an extremely important problem that we would also like to address. Our editorial policy emphasizes that replications, both direct and conceptual, of important findings established in the psychology of creativity are welcome and will be considered for publication.

Of course these three elements do not limit our expectations, hopes and plans. 
We do welcome studies from all levels and aspects of creativity: from very mini-c (Kaufman \& Beghetto, 2009) to eminent creativity, from case studies to massive quantitative works. We are open to theoretical papers and works that describe applications, programs and interventions. We plan to publish interviews with renowned creators and creativity researchers, as well as book reviews. As openness is the main characteristic of virtually all creative people, we admit it very seriously - we are really open to all kinds of interesting and high-quality works devoted to creativity.

\section{Call for commentaries}

Before we present this issue and the papers included in it, we would like to focus our readers' attention on the more specific call for commentaries. We are starting this new journal with a very specific first part, entitled Theories. It is comprised of three papers written by Vlad Petre Glăveanu from Aalborg University, Denmark, Izabela Lebuda from the Academy of Special Education, Poland, as well as Michael Chruszczewski from the University of Warsaw, Poland. These three papers share something in common - all are thought-provoking, controversial at certain points, and posted in the main as "positionpapers" presenting the Authors' personal ideas and experiences in the field. We invite all interested scholars to share their opinions and comments regarding any of these three papers. In the near future we plan to publish special issues related to the condition of the psychology of creativity and the question of whether it is really a field in crisis (see Glăveanu's paper). It is also our intention to publish a special issue dealing with the status of research on big- $\mathrm{C}$ creativity in the creativity literature, especially the costs associated with studying higher level creative achievement and its role for psychology and education (see Lebuda's paper). Another special issue we are planning will be devoted to the old, but still controversial topic of the associations between creativity and mental illness (see Chruszczewski's paper). We welcome all commentaries of no more than 1,500 words (including abstract, references, possible tables and figures) submitted by the end of the October 2014.

\section{This issue}

This issue consists of eleven papers written by scholars who mainly represent Poland, but also Denmark and Romania (Vlad Petre Glăveanu who is opening this issue is a Romanian scholar working in Denmark). Part I -Theories - is composed of the aforementioned articles by Glăveanu (“The psychology of creativity: A critical reading"), Lebuda ("Big C Research - The Big Challenge? Reflections from research into eminent creativity in the light of the investment theory of creativity") and Chruszczewski ("The creative side of mood disorders"). These papers are not void of controversies, but we do see their 
great potential for evoking a fruitful and constructive discussion based on the ideas presented there. Part II - Research - is composed of four papers, and presents empirical studies conducted within qualitative (Chmielińska \& Modrzejewska-Świgulska) or quantitative paradigms (Nowacki; Szen-Ziemiańska; Pufal-Struzik \& Szewczyk). Bartłomiej Nowacki discusses the timely problem of creativity styles and describes the first steps toward adapting an instrument for measuring different styles of creativity in accordance with Galenson's theoretical model. Joanna Szen-Ziemiańska, places her research within the psychology of science and discusses the structure of self-beliefs concerning scientific work and their consequences for creative activity and achievement in science. Aleksandra Chmielińska and Monika Modrzejewska-Świgulska present the results of qualitative discussions with teachers concerning the barriers to innovative activity in- and out-of-the school. Irena Pufal-Struzik and Agnieszka Szewczyk focus on the relationship between adolescents' creative attitudes and their perception of family functioning. Part III - Applications - includes four articles which mainly deal with art and showing how creativity works in different settings. Anna Boguszewska attempts to build bridges between famous artists' styles of work and their educational consequences for teaching and didactic activity in a broad sense. Similarly, Ewa Tomaszewska presents her experiences with the application of art-based activity realized in a theatre setting, as a way of enriching the creative activity of children. Beata Sokolowska-Smyl, analyzes the role of early childhood experiences for the creativity of one of the most creative Polish painters of XX century Zdzislaw Beksinski. Finally, Czeslaw Dziekanowski closes this issue with an excerpt from his prose - an example of creative work in a creativity journal.

The work on this issue took us longer than we had initially expected, but it would not have been possible without the great enthusiasm of our authors and the priceless assistance of our reviewers - members of our Editorial Board. We also turned to external, ad hoc experts for comments. We appreciate their help and the quality of the comments we received.

Beginnings are frightening, but also intriguing. We believe we are beginning a new initiative that will turn into a fascinating adventure. We would be happy if you were to take part in this adventure together with us. Enjoy reading this issue, but also remember our invitation to create this journal with us. 


\section{REFERENCES}

Glăveanu, V. P. \& Karwowski, M. (2013). Joining the Debate: Creativity seen from Eastern and Central Europe. International Journal of Creativity and Problem Solving, 23, 5-11.

Karwowski, M. \& Glăveanu, V. P. (Eds.) (2013). Creativity in Central and EasternEuropean perspectives. Special issue of International Journal of Creativity and Problem Solving, 23.

Kaufman, J. C. \& Beghetto, R. A. (2009). Beyond big and little: The four C model of creativity. Review of General Psychology, 13, 1-12.

Kaufman, J. C. \& Sternberg, R. J. (Eds.) (2006). The International Handbook of Creativity. New York, NY: Cambridge University Press.

Makel, M. C. (2014). The empirical march: Making science better at self-correction. Psychology of Aesthetics, Creativity, and the Arts, 8, 2-7.

Corresponding author at: Maciej Karwowski, Department of Educational Sciences, Academy of Special Education, 40 Szczesliwicka St., 02-353 Warsaw, Poland.

E-mail: maciek.karwowski@gmail.com

Corresponding author at: Janina Uszyńska-Jarmoc, Faculty of Pedagogy and Psychology, University of Bialystok, 20 Świerkowa St., 15-328 Bialystok, Poland.

E-mail: j.uszynska@uwb.edu.pl 